antitrypsin level. ${ }^{3}$ These three conditions have well described lung involvement and the common occurrence of antitrypsin deficiency may have important implications. This problem is now under investigation in this laboratory.-We are, etc.,

\section{O. FitzGerald.}

\section{K. F. MCGEENEY.}

B. Gilhooly.

Department of Medicine and Therapeutics,
University College, University College,
Dublin 4.

REFERENCES

1 Dietz, A. A., Hodges, L. K., Rubinstein, H. M., and Briney, R. R., Clinical Chemistry, 1967,

13, 242.
Evans. H. E., Levi, M., and Mandl, I., American
Review of Respiratory Disease, i970, 101, 359 .
3.565, 3 Eriksson. S., Acta Medica
177, Suppi. No. 432, p. 1.

\section{Male Sterilization}

SIR.-Dr. Pauline Tackson and others (31 Octoher, p. 295) require two semen analyses to show azonsvermia at an interval of one month. In order to avoid the patient having to use contraceptives longer than necessary, it is perfectly reasonable to ask for two specimens at an interval of 7-14 days-that is, long enough to allow the seminal vesicles to fill uo again.

After vasectomy, I ask that at least two months shall have elansed since the operation, and that he shall have ejaculated at least 15 times. After that. he should not ejaculate for at least three davs, in order to produce the biggest possible specimen straight into a $50-\mathrm{ml}$. container which has a wide mouth. and is provided by the laboratorv. If that is clear, a second specimen is reauested 7-14 days later. If one of those is not clear, he is sent another container for use not before 10 days have elapsed and after he has had at least another five ejaculations. When two consecutive specimens have been found free of snerm, contraceptive nrecautions can be abandoned.

The object of asking for two specimens is to make assurance doublv sure. and to satisfv a court of law in the event of litigation. ${ }^{1}$ It is not to check whether recanalization has taken place. Hanlev ${ }^{2}$ has shown that this takes considerably longer.

As a matter of terminology, aspermia, which means complete absence of sperm, seems a more accurate term than azoospermia, which means absence of living sperm and implies that non-motile sperm can be present.-I am, etc.,

\section{H. C. M. Walton.}

Beck Laboratory.
Swansea Hospital

\section{REFBRENCES}

1 Constable. H., Lancet, 1968, 2, 1246

\section{Phentolamine in Heart Block}

SIR,-I am prompted by the recent remarks in your columns ( 31 October, p. 307 , and 28 November, p. 558) about the drug treatment of heart block to comment that, in my experience, a short course of a glucocorticoid (such as prednisolone, starting at $\mathbf{4 0} \mathrm{mg}$. per day) will nearly always change $A / V$ block (complete or incomplete) and/or bundle branch block (left or right, complete or incomplete) back to sinus rhythm when the conduction fault follows a recent myocardial infarction.

Presumably the action of the drug is to reduce oedema, as it will do in uncomplicated cerebral oedema following concussion.-I am, etc.,

\section{J. H. MitcheLl.}

Caithness Central Hospital,
Wick, Caithness.

\section{Colistin Sulphomethate Sodium and Renal Function}

SIR,-We refer to the paper by Mr. D. J. E. Price and Dr. D. I. Graham (28 November, p. 525) where the summary appeared to misrepresent the actual findings. We wish to point out that although the authors considered renal failure to have contributed to the final cause of death in some cases, which it should be noted were severely ill patients with refractory infections when treatment was started, in only one case was renal failure the actual cause of death in this difficult group of cases receiving exceptionally high dosages of colistin.

Furthermore, no mention was made in the summary of the reversible nature of the biochemical changes which occurred following colistin, as indicated by the findings in all patients who survived, including those considered to have developed acute tubular necrosis and as suggested by the available biochemical data in those patients who died. In our opinion the summary does therefore not accurately portray the content of this paper.-We are, etc.,

\section{Eustace Sproston. M. P. MCCONNELL.}

\section{Medical Department, Charmax Ltd.,}

*** We have shown the above letter to $\mathrm{Mr}$. D. J. E. Price and Dr. D. I. Graham who reply: "We would like to thank Dr. E. Sproston and Mr. M. P. McConnell for drawing to our attention that our summary was incomplete. As they have rightly pointed out, the high dosages of colistin used produced completely reversible nephrotoxicity in the surviving patients even though the biochemical data suggested that it had produced acute renal failure in some and acute tubular necrosis in others. In those patients who died there was an indication that the nephrotoxicity was also reversible, and again we would like to stress that renal failure may have contributed to the fatal outcome in some of our patients but in the majority they died from the primary neurological disease."-ED., B.M.f.

\section{Accident and Emergency Services}

SIR,-I have followed the recent correspondence on the accident and emergency services with interest, and from the viewpoint of a career appointment in this branch of hospital medicine would like to make a few observations.

I am afraid that I cannot confirm that three quarters of the patients attending the casualty department of this hospital could be regarded as general practitioner cases. Letters from Mr. F. C. Durbin and Dr R. W. Stephenson (28 November, p. 557) prompted me to make a quick check by selecting a week at random and analysing all the attendances. Total attendances were 443 , of which 226 were new cases. Of these latter 12 could have been dealt with by a general practitioner by examination and prescription only and an additional 42 could possibly have been dealt with if every general practitioner had 24-hour facilities for minor suturing, dressing small burns, strapping minor sprains, incising paronychiae, etc. Even this latter maximum figure only represents 7 to 8 patients a day. Of patients referred to other faculties for admission or outpatients follow-up 36 were orthopaedic and 28 for other departments.

To subdivide the work into "orthopaedic" or "general practitioner," as suggested by Dr. Stephenson, is an oversimplification, as it does not easily accommodate such cases as the ruptured spleen or spontaneous pneumothorax. Many emergencv ambulance cases will involve other specialties and will require assessing and possibly immediate medical treatment or even resuscitation. Someone will be required to receive and assess such cases, including those of multiple trauma, at the same time rendering the condition non-urgent before referring to the relevant specialty. This person will also be able to deal with the less severe trauma and illnesses that can have a high morbidity if not treated vigorously.

To effectively liaise with senior members of other departments, with general practitioners, ambulance, and other outside services it is surely a considerable advantage to have a permanent member of staff in the department, and with junior medical and ancillary staff this person can then run the department and represent its interests first hand. That this requires experience and training is recognized by Mr. Durbin's suggested "special crash courses of training." So if the person will end up as a "specialist" why not a "consultant"?-I am, etc.,

$$
\begin{aligned}
& \text { St. Martin's Hospital, } \\
& \text { Bath. }
\end{aligned}
$$

R. SNOoK.

\section{Survival Rates with Dialysis}

STR,-I read with interest the article by $\mathrm{Dr}$. J. F. Moorhead and colleagues on survival rates of dialvsis and transplantation (10 October, p. 83). While sympathising with the difficulties that the authors must have had in compiling data going back seven years when none of them was actively involved in the early years of this work, I nevertheless feel that it is necessary to add three apparently unreported early deaths in the hospital series.

In September 1963 a male patient aged 20 died after five months of treatment from inhalation of blood following epistaxis associated with heparin. In December 1963 a male patient ${ }^{1}$ aged 35 died after 10 months from a massive right heart embolus associated with the use of indwelling femoral catheters, and in March 1966 a male patient died aged 45 after three weeks' treatment from a cardiac tamponade. I could not find any mention of these deaths in their mortality analysis. Furthermore, 